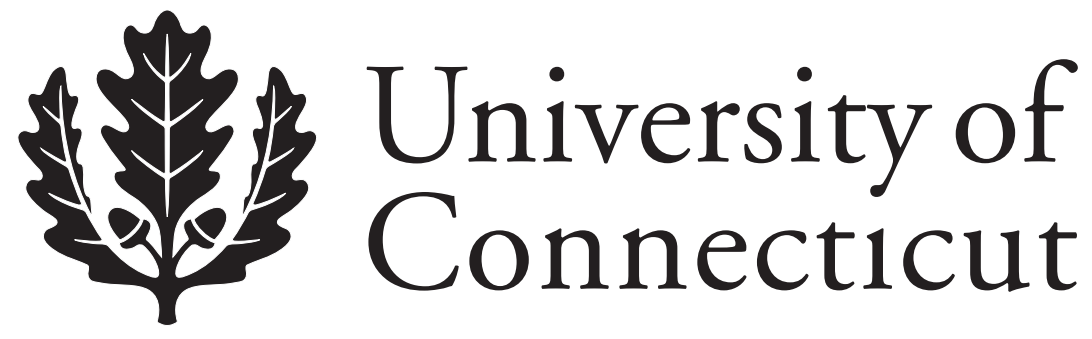

Department of Economics Working Paper Series

The Real Puzzle of Blackmail: An Informational Approach

Thomas J. Miceli

University of Connecticut

Working Paper 2010-08

April 2010

341 Mansfield Road, Unit 1063

Storrs, CT 06269-1063

Phone: (860) 486-3022

Fax: (860) 486-4463

http://www.econ.uconn.edu/

This working paper is indexed on RePEc, http://repec.org/ 


\begin{abstract}
The "puzzle" of blackmail is that threats to reveal private information that would be harmful to someone in exchange for money are illegal, but revelation is not. The resolution is that concealment of information about product quality impedes the efficient operation of markets, whereas revelation promotes it. The real puzzle is why possessors aren't naturally inclined to sell to uninformed parties, who value the information more than would-be blackmail victims. The answer has to do with the public good qualities of information, which create an appropriability problem in transactions with uninformed parties. The paper also discusses incentives to acquire compromising information.
\end{abstract}

Journal of Economic Literature Classification: D82, K42

Keywords: Asymmetric information, blackmail, adverse selection 


\section{The Real Puzzle of Blackmail: An Informational Approach}

“...an illustrious client has placed her piteous case in my hands. It is the Lady Eva Blackwell, the most beautiful debutante of last season. She is to be married in a fortnight to the Earl of Dovercourt. This fiend [Charles Augustus Milverton] has several imprudent letters...nothing worse-which were written to an impecunious young squire in the country. They would suffice to break off the match. Milverton will send the letters to the Earl unless a large sum of money is paid him."

Sherlock Holmes describing a case of blackmail that he is investigating in

"The Adventure of Charles Augustus Milverton," Doyle (1986, p. 793)

\section{Introduction: The Puzzle of Blackmail}

The above case illustrates the prototypical case of blackmail: a third party has somehow acquired information that is damaging to one of two other parties who are about to engage in a transaction. The third party then solicits a payment from the jeopardized party in return for keeping the information secret. Economists, when viewing this situation dispassionately, regard the illegality of blackmail as something of a puzzle. Why, they would argue, is a transaction that on its face is consensual regarded as a crime? Legal scholars too have struggled to explain why threats to reveal information in exchange for money are punishable when the act of revealing the information would itself be perfectly legal. Several theories have been advanced to resolve this "paradox of blackmail."1

One argument is simply that the transaction, because it involves a threat, is not truly consensual on the part of the jeopardized party. In law, contracts are unenforceable when entered into under coercion or duress, as when someone points a gun at your head and says "your money or your life." Based on this logic, however, a seller might similarly argue that he only agreed to lower his price after a prospective buyer threatened to patronize a competitor down the block, but such a claim would surely not be grounds, in law or economics, for requiring the

\footnotetext{
${ }^{1}$ See, for example, the special issue of the University of Pennsylvania Law Review (Vol. 141, No. 5, May 1993), which is devoted to both a legal and economic analysis of blackmail. Also see Helmholz (2001), who examines the Roman law of blackmail.
} 
buyer to indemnify the seller for the reduced price. ${ }^{2}$ Thus, the presence of a "threat" per se cannot be the crucial element of blackmail. Others have argued that allowing blackmail would provide an incentive for individuals to invest resources in acquiring information that is not socially productive (Ginsburg and Shechtman, 1993). ${ }^{3}$ While this argument has merit in the sense that the information in question is concealed by the blackmail transaction, it is not necessarily the case that the information is not socially valuable. In fact, I will argue in this paper that the information generally is socially valuable, at least in the prototypical case to be examined, though the private value to the acquirer will not generally coincide with its social value, whether or not blackmail is legal.

The reason information is socially valuable in the prototypical case is that markets fail to operate efficiently in the presence of asymmetric information due to adverse selection problems (Akerlof, 1970). As a consequence, the acquisition and disclosure of information prior to trade can increase the efficiency of trade (Shavell, 1994). However, the acquirer will not necessarily internalize this value because of the nature of information as a tradable good. In particular, because information has public good qualities, would-be sellers of information generally lack secure property rights in it (Cheung, 1982; Isenbergh, 1993). I will argue that this creates a strong incentive for possessors of information to seek to profit from its concealment (because the jeopardized party already knows the information) rather than from its disclosure, even when the overall gains from disclosure exceed the gains from concealment. This, I will argue, represents the real economic reason for outlawing blackmail.

The remainder of the paper is organized as follows. Section 2 describes the prototypical blackmail case as a proposed transaction between two parties in the presence of asymmetric

\footnotetext{
${ }^{2}$ Posner (1977) discusses the law and economics of such "threats."

${ }^{3}$ In addition, it will induce potential blackmail targets (e.g., politicians and other individuals in the public eye) to invest in unproductive efforts to avoid being blackmailed (Posner, 1993).
} 
information. Section 3 then shows that disclosure of information will be welfare-enhancing because it eliminates the welfare loss arising from the informational asymmetry. It also shows that the uninformed party will be willing to pay more for the information than the informed (jeopardized) party precisely because disclosure is efficient. Thus, the question arises as to why the blackmailer does not automatically seek to sell the information to the higher valuing (uninformed) party. Section 4 answers that question by arguing that property rights in information are not secure because of its public good nature. That is, the blackmailer may have to reveal his information in the process of trying to sell it. Because of this, he will be inclined, absent a law prohibiting it, to transact with the informed party instead, given that the latter already knows the information. Section 5 turns to the issue of acquisition of the information and shows that, although the information is socially valuable in the sense described above, its private value to acquirers will not generally coincide with its social value, even when blackmail is illegal. Finally, Section 6 concludes.

As a final point, I note that this paper is not meant to examine the multifarious legal and moral dimensions of blackmail, nor even all of its economic aspects. ${ }^{4}$ Rather, its intent is simply to clarify the informational aspects of blackmail and to gain insight into the real economic basis for its illegality.

\section{The Puzzle of Blackmail: An Informational Model}

The model I will use to examine the efficiency of laws prohibiting blackmail involves a proposed "transaction" between two parties, a buyer B and a seller S. Thus, the source of the

\footnotetext{
${ }^{4}$ For example, I do not touch on the credibility of blackmail threats (see Shavell (1993), Gomez and Ganuza (2002), and the cogent discussion of this issue in the Sherlock Holmes story quoted at the beginning of this article), or the possible function of blackmail as a form of private law enforcement (see Landes and Posner (1975) and Posner (1993)).
} 
"damage" to the victim (S) will be entirely in the context of any lost gains from the transaction that disclosure would either prevent from occurring or cause to be renegotiated. I therefore do not consider situations in which the victim of blackmail is in jeopardy of criminal punishment for a past undiscovered crime (the scenario discussed by Landes and Posner (1975, pp. 42-44)), or would suffer a public embarrassment from disclosure of certain personal information.

Suppose that the gross value of the proposed transaction to the buyer is $v$, representing his maximum willingness to pay, while the reservation price of the seller is $r$. In the absence of any impediments to bargaining (such as uncertainty about the quality of "good" being exchanged), the transaction will occur if and only if $v \geq r$, and that outcome will also be efficient in the sense that it produces a surplus of $v-r$. If we assume a continuum of buyers and sellers, where $r$ varies across sellers according to the distribution function $F(r)$, while $v$ is fixed for all buyers, then transactions will occur up to the point where $v=r$. The aggregate (seller's) surplus from all of the transactions is therefore given by

$$
S_{1}=\int_{0}^{v}(v-r) f(r) d r
$$

which is the maximum amount available.

Now add a "quality" dimension to the transaction. Suppose in particular that sellers come in two types: "low quality" and "high quality", where buyers value a transaction with a low quality seller at a lower amount, say $v-\delta$, where $\delta$ is the fixed discount. If buyers can distinguish between the two types of sellers, the market will become segmented, with transactions involving high quality sellers continuing to occur up to the point where $v=r$, and transactions involving low quality sellers only occurring up to the point where $v-\delta=r$. Let $\alpha$ be the fraction of high quality sellers in the population of sellers, and assume that the distribution of seller reservation prices is 
the same for both types. Then the aggregate expected surplus from all successful transactions is given by ${ }^{5}$

$$
S_{2}=\alpha \int_{0}^{v}(v-r) f(r) d r+(1-\alpha) \int_{0}^{v-\delta}(v-\delta-r) f(r) d r
$$

which again is the maximum available surplus (though it is obviously less than the amount in (1) where all sellers were of high quality). Figure 1 illustrates the outcome in the market for high quality (panel (a)) and low quality (panel (b)) sellers. Note in particular that transactions involving high quality sellers occur up to $r_{h}{ }^{*}$, while transactions involving low quality sellers only occur up to $r_{l}^{*}<r_{h}{ }^{*}$.

[Figure 1 about here]

Now consider the case where buyers cannot distinguish between high and low quality sellers. Since sellers appear outwardly identical, there must now be a single market rather than a segmented market, and prospective buyers will offer at most $v-(1-\alpha) \delta$ to enter into a transaction with a randomly chosen seller. Transactions will therefore occur up to the point where $v-(1-\alpha) \delta=r$, yielding an aggregate surplus equal to

$$
S_{3}=\alpha \int_{0}^{v-(1-\alpha) \delta}(v-r) f(r) d r+(1-\alpha) \int_{0}^{v-(1-\alpha) \delta}(v-\delta-r) f(r) d r
$$

The welfare loss arising from the unobservability of seller types can be calculated by forming the difference between (2) and (3):

$$
S_{2}-S_{3}=\alpha \int_{v-(1-\alpha) \delta}^{v}(v-r) f(r) d r+(1-\alpha) \int_{v-\delta}^{v-(1-\alpha) \delta}[r-(v-\delta)] f(r) d r
$$

which is strictly positive. The first term on the right-hand side is the foregone surplus from transactions involving high quality sellers who inefficiently exit the market because they are undervalued, while the second term is the net loss from transactions involving low quality sellers

\footnotetext{
${ }^{5}$ It does not matter what the specific price per transaction is. I simply assume that all transactions promising a surplus actually occur.
} 
who inefficiently remain in the market because they are overvalued. The overall loss represents the standard inefficiency associated with adverse selection (Akerlof, 1970).

It should be obvious that in this setting, high quality sellers have an interest in revealing their types to buyers prior to contracting, while low quality sellers would like to conceal their types. If high quality sellers can reveal their types credibly and at low cost, it will go a long way toward eliminating the above inefficiencies because then, low quality sellers will no longer be able to profit by pretending to be of high quality. The above equilibrium will thus unravel. In many contexts, however, disclosure will not be possible or believable, especially when the information that a seller would like to reveal is the absence of a defect. For example, in the case of a proposed marriage, a prospective spouse would like to prove that he or she has not engaged in certain disreputable behavior in the past. Generally, this will be difficult or impossible to do. We assume hereafter that this is the case in the current setting.

On the other hand, proving that a seller is of low quality will often be an easy matter (as the above quote from the Sherlock Holmes story suggests), but low quality sellers will obviously have an interest in preventing that information from becoming public. The typical blackmail case involves a third party who acquires evidence that a particular seller is of low quality, and then seeks a payment from that seller in return for not revealing that information to the buyer. As noted, the puzzle of blackmail is why such a transaction is illegal.

\section{Resolving the Blackmail Puzzle}

The obvious answer to the blackmail puzzle suggested by the above analysis is that a transaction whose objective is to conceal information about a seller's type prior to contracting impedes the efficient operation of markets in the presence of asymmetric information. As the 
analysis showed, the ability of low quality sellers to conceal information about their types prior to exchange allows some inefficient transactions to occur and other efficient ones to be foregone. Thus, any resources expended by third parties to acquire such information in hopes of colluding with sellers to keep that information private is socially wasteful and therefore should be discouraged. The illegality of blackmail makes perfect sense when seen in this light. This point, of course, has been previously made (Ginsburg and Shechtman, 1993).

Whereas concealment of information about seller types impedes efficiency, disclosure promotes it. Thus, the discovery and sale of such information to prospective buyers would be potentially welfare-enhancing because it would allow buyers to properly price their transactions and to forego those that do not promise a surplus. In contrast to blackmail, such transactions prior to trade are legal, but they present two practical difficulties: first, third parties possessing the information might still prefer to sell it to low quality sellers rather than to buyers (for reasons to be described below), and second, the incentive to acquire the information in the first place may not be socially efficient. I address these issues in turn. To do so, I first need to calculate the amount that low quality sellers, and prospective buyers, are willing to pay for the information about seller types. ${ }^{6}$

As noted, low quality sellers would pay to conceal information about their types. In terms of the above model, sellers will pay up to the aggregate surplus they expect to receive as a result of the buyer's uncertainty. This consists of two components. The first is the premium sellers receive above the maximum amount buyers would pay to transact with them under certainty. The aggregate amount of this premium is the difference between buyers' willingness

\footnotetext{
${ }^{6}$ I will not consider the value of information to high quality sellers who would pay to reveal their types, based on the above assumption that it is impossible for sellers to prove the absence of a defect. Obviously, in those setting where such information can be verified, high quality sellers will either reveal it themselves (directly or by signaling (Spence, 1973)), or though devices such as licensing that will emerge to serve the same purpose (Leland, 1979).
} 
to pay under uncertainty, $v-(1-\alpha) \delta$, and their willingness to pay under certainty, $v-\delta$, for those sellers who would remain in the market at this lower price. The total amount of this price premium is given by

$$
\int_{0}^{v-\delta} \alpha \delta f(r) d r
$$

and is shown by area A in Figure 2. The second component of sellers' willingness to pay is the surplus that would be lost by those sellers who would drop out of the market if buyers could observe their types and only offered $v-\delta$. The amount of this lost surplus would be

$$
\int_{v-\delta}^{v-(1-\alpha) \delta}[v-(1-\alpha) \delta-r] f(r) d r
$$

and is shown by area B in Figure 2. Summing these expressions yields the aggregate willingness to pay of low quality sellers to conceal information about their types:

$$
W_{s}=\int_{0}^{v-\delta} \alpha \delta f(r) d r+\int_{v-\delta}^{v-(1-\alpha) \delta}[v-(1-\alpha) \delta-r] f(r) d r
$$

[Figure 2 about here]

Now consider the amount buyers who are transacting with low quality sellers would be willing to pay to learn information about seller types. One component would obviously be the amount in (5) (area A in Figure 2) since that is simply a transfer payment from buyers to low quality sellers that informed buyers would no longer be willing to pay (though they would continue to transact with sellers on this range). The second component is the premium buyers pay to sellers over the range where transactions that would have occurred at the higher price no longer take place because sellers on this range are unwilling to sell at the lower price. This amount is given by the sum of areas $\mathrm{B}+\mathrm{C}$ in Figure 2. Thus, the total willingness to pay of buyers is

$$
W_{b}=\int_{0}^{v-(1-\alpha) \delta} \alpha \delta f(r) d r
$$

which is the sum of areas A, B, and C in Figure 2. 
Notice therefore that buyers are willing to pay more than sellers in aggregate for information about seller types. The reason for the difference is that if the information is revealed, marginal sellers exit the market, thereby mitigating their losses, whereas if the information remains private, buyers pay the full premium for all sellers, including those who inefficiently remain in the market. The excess amount that buyers would offer over sellers is given by the difference between (8) and (7), or

$$
W_{b}-W_{s}=\int_{v-\delta}^{v-(1-\alpha) \delta}[r-(v-\delta)] f(r) d r .
$$

This amount corresponds to area $\mathrm{C}$ in Figure 2, and represents the welfare loss from those transactions that inefficiently occur as a result of imperfect information on the part of buyers. ${ }^{7}$ Thus, buyers are willing to pay more than sellers to discover information about seller types precisely because disclosure of that information is socially beneficial in the sense that it prevents some inefficient transactions from occurring. The extra amount buyers are willing to pay over sellers (area C in Figure 2) therefore represents the welfare loss that would be saved by making the information public.

While this conclusion explains the illegality of blackmail, it raises the following question: if buyers as a group are willing to outbid sellers for information about seller types, why is it necessary to make transactions with sellers illegal? In other words, why won't third parties in possession of information about seller types naturally seek to sell that information to uninformed buyers, who, as we have seen, value that information more than sellers and therefore would outbid them for it? This is what I mean by the "real" puzzle of blackmail.

\footnotetext{
${ }^{7}$ There is a corresponding welfare loss from those transactions involving high quality sellers that are foregone. As noted, however, we assume that this inefficiency cannot be eliminated by the sort of transactions that we are considering.
} 


\section{Resolving the Real Puzzle of Blackmail: Property Rights over Information}

The resolution to the puzzle has to do with the nature of transactions involving information. It is well-established that the production and transfer of information presents problems in ordinary market settings because of the publicness of information, or the fact that information, once produced, can be profitably used by many individuals without diminishing its quantity. The problem this creates is that discoverers of information will have difficulty in appropriating its full social benefits. This "appropriability problem" provides the motivation for patents and copyrights, which give exclusive rights to innovators and authors to profit from their creations, at least for a prescribed period of time.

What does this have to do with blackmail? Think of the third party who is in possession of information about seller quality. He is like an inventor who discovers an idea that he thinks might be valuable to a firm for commercial purposes. But how can he convince the firm of the idea's value except by disclosing it to the firm? In other words, the discoverer is in the position of essentially having to give his idea away in the process of trying to sell it (Cheung, 1982; Hirshleifer and Riley, 1992, pp. 273-274). In the above model, the third party possessor of seller information is in the same position relative to buyers. A buyer will only be willing to pay for the information after having been convinced of its value, but once he learns the information, he has no need to pay for it.

Note, however, that the appropriability problem does not impede the third party's ability to profit from a transaction with sellers because the latter already know the information. In fact, low quality sellers will want assurances that the third party will not continue to seek payments for his silence in the future (Shavell, 1993). It follows that possessors of incriminating evidence will be inclined to bargain with sellers rather than buyers in order to avoid the appropriability 
problem. This logic resolves the real puzzle of blackmail and provides a further economic rationale for laws against blackmail. ${ }^{8}$

\section{The Acquisition of Information}

Finally, consider the incentive for third parties to uncover incriminating information about seller types in the first place. (Recall that one argument for the illegality of blackmail is that such acquisition is inefficient.) First note that the social value of information about low quality sellers corresponds to the welfare loss in (9), or area C in Figure 2. Since this amount is positive, it is socially efficient for a third party to acquire information and reveal it if the cost of acquisition, say $k$, is less than the value in (9). The actual incentive to acquire information, however, will depend on its private value compared to the cost of acquisition. ${ }^{9}$

As noted, the private value of a transaction with low quality sellers-a blackmail transaction - is given by the willingness to pay of sellers in (7), or area A+B in Figure 2. Since this amount may well exceed $k$, such transactions need to be outlawed since they clearly have no social value. This is the argument advanced by Ginsburg and Shechtman (1993).

The private value of information if it is instead intended to be sold to buyers is given by (8), or area $\mathrm{A}+\mathrm{B}+\mathrm{C}$ in Figure 2. Although information is socially valuable in this case, its private value is clearly larger than the social value by the amount of area $\mathrm{A}+\mathrm{B}$, implying that third parties, if they expect to be able to capture the full value of that information in their dealings with buyers, will have an excessive incentive to acquire information from a social perspective. (Their overinvestment thus amounts to rent-seeking.) The reason is that acquirers

\footnotetext{
${ }^{8}$ Isenbergh (1993) also discusses the issue of property rights over information in the context of blackmail.

${ }^{9}$ On the social versus private value of information, see Hirshleifer (1971) and Shavell (1994).
} 
would invest in too much effort to acquire information is that they ignore the offsetting cost to low quality sellers of revealing information about their types to buyers.

Interestingly, however, the fact that third parties are unlikely to be able to capture the full value of their information when dealing with buyers (for the reasons noted above) actually works in the right direction to curb their excessive incentive to acquire it in the first place. Once this factor is accounted for, it is not possible, as a general proposition, to say whether acquirers will over- or underinvest in information acquisition prior to trade.

\section{Conclusion}

This paper has argued that the "puzzle" of blackmail is resolved, at least in certain contexts, by the fact that efforts to conceal information about seller "quality" in the presence of asymmetric information reduces the efficiency of the market mechanism according to the wellknown adverse selection effect. In this context, transactions that promote concealment of information are clearly undesirable from an economic perspective. A careful analysis of this situation, however, reveals another puzzle: namely, in such settings, the value of information about seller types is higher to uninformed buyers than it is to sellers (by virtue of the inefficiency of concealment), suggesting that third parties possessing information about seller quality should naturally want to sell the information to buyers (in other words, reveal it), thereby promoting efficiency. It would seem to follow that laws against blackmail are largely unnecessary.

The resolution of this puzzle is that property rights to information vis-à-vis buyers (uninformed parties) are not secure given the public good nature of information. In particular, the process of trying to convince buyers of the value of the information will necessarily reveal it to them, thus making it difficult for third parties to profit from sale of the information. No such 
"appropriability problem" plagues a blackmail transaction aimed at concealing the information because the "victim" of the blackmail obviously already knows the information. Thus, laws to forbid such transactions appear necessary after all.

Finally, the paper examined the incentives to acquire the information in the first place. It showed that the information is socially valuable in the sense that disclosure would improve market efficiency, but that the private value of the information to third parties will generally exceed its social value, even when acquirers intend to disclose it. The reason is that acquirers ignore the cost of disclosure to "victims." Still, we argued that third parties may not have excessive incentives to acquire information because of the difficulty in appropriating its benefits. 


\section{References}

Akerlof, George. 1970. The Market for "Lemons": Quality Uncertainty and the Market Mechanism. Quarterly Journal of Economics 84 488-500.

Cheung, Steven, 1982. Property Rights in Trade Secrets. Economic Inquiry 20 40-53.

Doyle, Arthur Conan. 1986. Sherlock Holmes: The Complete Novels and Stories, Volume 1. New York: Bantam Books.

Ginsburg, Douglas, and Shechtman, Paul, 1993. Blackmail: An Economic Analysis of the Law. University of Pennsylvania Law Review 141 1849-1876.

Gomez, Fernando, and Ganuza, Juan-Jose, 2002. Civil and Criminal Sanctions against Blackmail: An Economic Analysis. International Review of Law and Economics 21 475498.

Helmholz, R.H., 2001. The Roman Law of Blackmail. Journal of Legal Studies 30 33-52.

Hirshleifer, Jack. 1971. The Private and Social Value of Information and the Reward to Inventive Activity. American Economic Review 61 561-574.

Hirshleifer, Jack, and Riley, John, 1992. The Analytics of Uncertainty and Information. Cambridge, UK: Cambridge Univ. Press.

Isenbergh, Joseph, 1993. Blackmail for A to C. University of Pennsylvania Law Review 141 1877-1903.

Landes, William, and Posner, Richard, 1975. Private Enforcement of Law. Journal of Legal Studies 4 1-46.

Leland, Hayne, 1979. Quacks, Lemons, and Licensing: A Theory of Minimum Quality Standards. Journal of Political Economy 87 1328-1346.

Posner, Richard, 1977. Gratuitous Promises in the Law. Journal of Legal Studies 6 411-426. , 1993. Blackmail, Privacy, and Freedom of Contrast. University of Pennsylvania Law Review 141 1817-1847.

Shavell, Steven, 1993. An Economic Analysis of Threats and their Illegality: Blackmail, Extortion, and Robbery. University of Pennsylvania Law Review 141 1877-1903.

, 1994. Acquisition and Disclosure of Information Prior to Sale. Rand Journal of Economics 25 20-36.

Spence, Michael, 1973. Job Market Signaling. Quarterly Journal of Economics 87 355-374. 


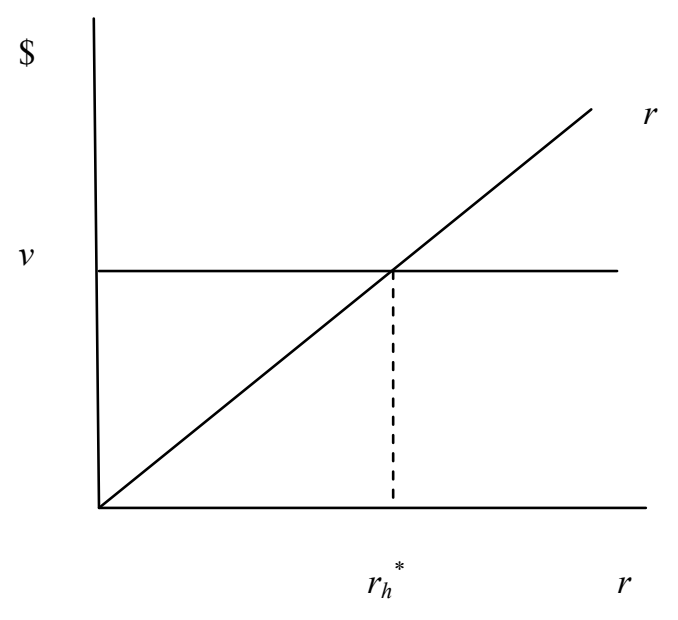

(a)

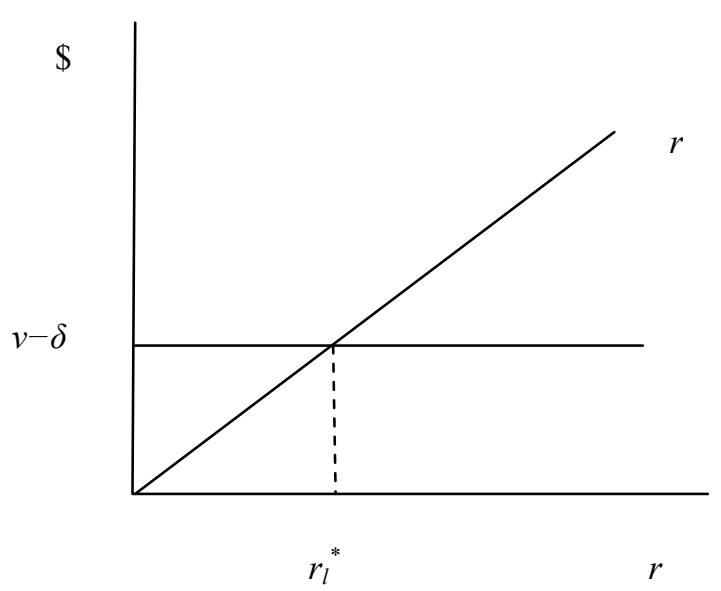

(b)

Fig. 1. Submarkets for high (a) and low (b) quality sellers under perfect information. 


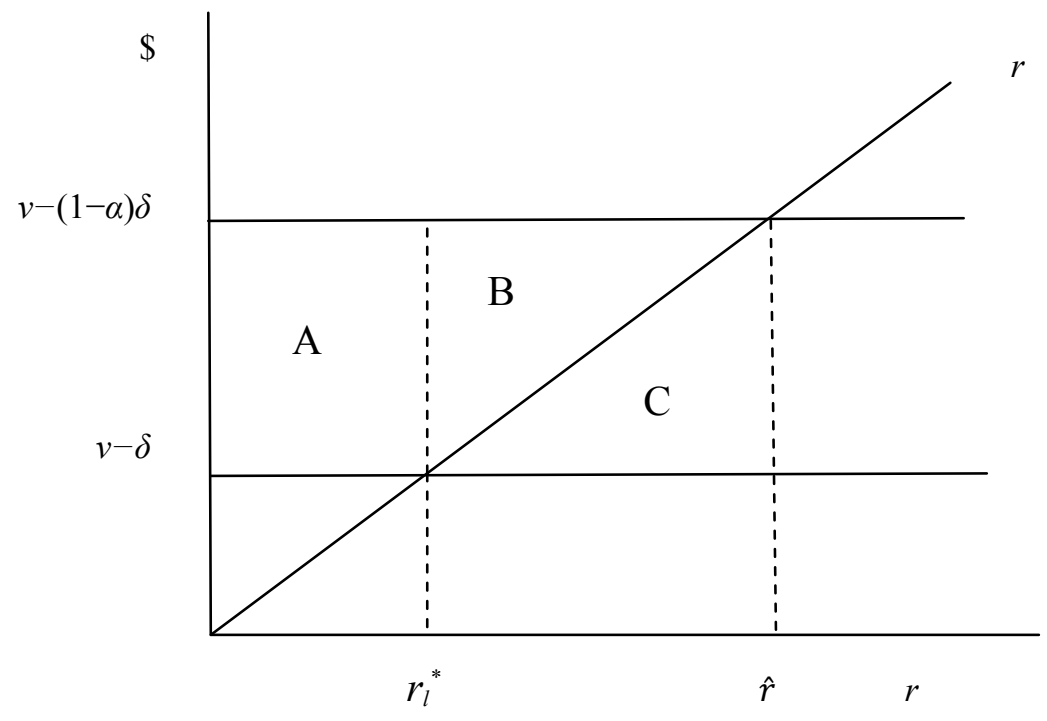

Fig. 2. Market for low quality sellers under asymmetric information. 